\title{
Anti-Luminous Mental States: Logical, Psychological and Epistemic Problems
}

\section{Óscar L. González-Castán ${ }^{1}$}

Received: 9 July 2020 / Accepted: 11 May 2021/Published online: 19 July 2021

(C) The Author(s) 2021

\begin{abstract}
In this paper I shall argue that Tim Williamson's argument for the anti-luminosity of many mental states faces difficult logical, psychological and epistemological problems. From a logical point of view, his argument is correct. However, the contrary argument that says that the anti-luminosity thesis does not necessarily follow from it is also correct. This opens a sceptical scenario. Hence, if Williamson wants to convince us that we should rationally prefer his argument rather than the other, he needs to add considerations that are not merely logical. These are psychological and epistemological in nature. However, none of these considerations is convincing.
\end{abstract}

Keywords Mental states $\cdot$ Scepticism $\cdot$ Antinomy $\cdot$ Psychophysical covariations $\cdot$ Partial sensitivity $\cdot$ Meta-knowledge

\section{Introduction}

Tim Williamson has argued that many mental states are non-luminous. This means that we might have them, in the sense of experiencing them, although we are not in a position to know what we are experiencing through them and even that we are experiencing them. If this is true, it is a challenging idea. According to traditional intentional analysis of mental states, under normal limitations I know the kind of mental state I am in - I feel cold now but I cannot remember how cold I was yesterday-and I also know what I feel-I feel cold but not hot. This intentional analysis leads us to distinguish in a seemingly uncontroversial way between the type of mental state we are currently in - feeling but not remembering — and its mental content, whether qualitative or conceptual - feeling cold but not hot. We usually know both things with absolute evidence or, at least, confidence. This core idea can be found in Aristotle, Descartes,

I would like to thank Antonio Benítez (U.C.M.) for helping me with the formalization of the logical proofs.

Óscar L. González-Castán

oscar.gonzalez@filos.ucm.es

1 Department of Logic and Theoretical Philosophy, Complutense University of Madrid, Madrid, Spain 
Brentano and Husserl but also in contemporary self-representational higher-order theories of consciousness (Kriegel, 2009; Kriegel \& Williford, 2006). Descartes thought that I know that I am doubting but not calculating and I know what I am doubting about. I am doubting about the existence of the world but not about other things. I can confidently answer the that-question and the what-question at the same time, and I know both things because I am the one who is consciously experiencing the mental state and its content. Ego cogito cogitata. I am peculiarly fused and related to both, although I am not identical either to my mental states or to their content. This peculiar fusion, although not complete identification, between the conscious self and his mental states can easily be seen because my state of feeling cold can change over time, and even disappear, but I do not necessarily disappear with my mental state of feeling cold. In Williamson's philosophical jargon, this intentional analysis implies that my mental states are luminous to us. Both the 'what' and the 'that' part of the mental state are luminous. However, if Williamson is right and many mental states are nonluminous, we need to detach our knowledge of these peculiar mental states or, at least, our knowledge of their contents, from our experience of them. There is no constitutive relationship between both things (Berker, 2008, p. 2, p. 11). Knowledge has its limits. If we take the previous intentional analysis as the grounds for understanding the philosophical challenge that Williamson is posing, we realize that he is addressing two related questions: (i) the anti-luminosity of the mental state in relation to our consciousness of it (we do not have introspective or reflexive knowledge of the existence of these mental states qua mental states when we experience them) and (ii) the anti-luminosity of the mental content that we are also experiencing when we are having that mental state. If Williamson is right, both are non-luminous because we cannot detach the feeling from what it is about, i.e. from its qualitative content. What makes Williamson's challenge philosophically appealing is that the mental states he is thinking about are not unconscious in any strong sense of the word, as this notion has often been used in the philosophy of mind. They are neither sub-personal computational or neurological states nor presently unconscious but potentially conscious ones. We experience these states but their content is certainly not luminous to us. Williamson's externalist views in epistemology lead him to summarize his ideas on anti-luminosity saying that since I experience the mental state, I somehow know it but I am not in the position to know that I know it (Williamson, 2000, p. 114). The mental state and its content are non-luminous.

\section{The Anti-luminosity Argument}

The example upon which Williamson rests his case is 'feeling cold' although he expands the results of his argument to other mental states like feeling pain, using two words with the same meaning, or to the fact that something appears to someone in the same way (Williamson, 2000, p. 96; Neta \& Rohrbaugh, 2004, Tennant, 2009). The novelty of his attempt is that he replaces phenomenological methodology and analytical tools in contemporary philosophy of mind (supervenience, analysis of the scope and reliability of introspection, relationship between awareness and knowledge, the problem of qualia, etc.) with an argument based on logical considerations whose result is at odds with most of what is 
broadly but, as often occurs in philosophy, problematically accepted in these areas of discussion.

Williamson's argument could hardly be shorter, just two pages long (Williamson, 2000, pp. 96-98). But first, the situation he bases his argument on.

I feel cold at dawn. As the sun rises and starts warming up the surface of the earth, I very, very gradually start feeling less and less cold. By early afternoon, I feel clearly hot or, as Williamson words it, I do not feel cold. This is supposed to be the description of a very common and uncontroversial experience. Complications arise when we think about how we should describe our cognitive relationship with the qualitative intentional contents of our mental states during the timespan that has passed between two luminous extremes, namely, at dawn when we felt cold and put our jacket on, and in the afternoon when we felt hot and took off our jackets.

These two extremes are luminous because I know very well what I feel. And the basis to get to know that I feel cold is that I just feel cold or, if you like, that I am aware that I feel cold. Feeling cold, being aware of feeling cold and knowing that one feels cold would come together in the same mental and epistemological package when we experience luminous mental states. In Berker's words:

There must be some sort of modal connection, constitutive or otherwise, between one's phenomenal experiences (such as one's feeling cold) and one's cognitive states (such as one's believing that one feels cold) - the phenomenal and the cognitive cannot swing apart from each other any which way one likes. (Berker, 2008, pp. 17-18)

However, if every time that I feel cold, I shall reliably know that I feel cold, then the condition of 'feeling cold' would be a luminous one at all times when I feel cold. And, in fact, 'feeling cold' seems to always be a luminous condition because I will be in the position to know that I feel cold, i.e. I shall be aware of it, at any time later on during the day, even at one millisecond interval, much in the same way that I was in a position to know that I feel cold when I stepped out of the house at dawn. But, is this so? According to Williamson's anti-luminosity argument, it is not. What is, then, the problem? The key point is to ask what happens with our feelings of hot and cold during the process of gradually getting less and less cold until we feel hot.

Williamson makes some assumptions to answer this question some of which are problematic: (i) these feelings actually change; (ii) they might change very, very slowly; (iii) this continuous and slow graduation makes us unaware of the fact that such tiny changes over very small periods of time have taken place (Williamson considers changes over one millisecond); (iv) these changes are unnoticed even though one tries to pay careful and full attention to how cold or hot one feels; and (v) nevertheless, we experience these gradual changes even though we are not in the position to know that we experience them.

In his argument, Williamson wants us to suppose that I shall also feel cold at time $t i$, say one millisecond later after having felt cold at $t 0$ when I went out of the house. One millisecond is not enough time to be aware of any change in my feelings of cold even though I might actually feel slightly less cold. Given the 
presupposition that 'feeling cold' is a luminous condition, I shall know that I feel cold at $t i$. And I shall know it, and hence shall believe it, with the same, or almost the same, confidence that I knew it before at $t 0$, because I am apparently in much the same luminous condition that I was one millisecond earlier. These seem to be very sensible presuppositions. Then Williamson's crucial steps to lead us towards the anti-luminosity thesis are as follows:

i. If I have knowledge, i.e. a true belief or a belief about which I am reasonably convinced, that I feel cold at $t i,(0 \leq i \leq n)$, I shall also believe that I feel cold at $t i+1$ since my mental states at $t i$ and $t i+1$ are sufficiently similar. In fact, I have to believe it because I am not aware of any changes between $t i$ and $t i+1$.

ii. If I know that I feel cold at $t i$, then it has to be true that I feel cold in a similar case $t i+1$, if my belief that I feel cold at $t i$ is reasonably convincing, as (i) says. In other words, 'if one does not feel cold at $t i+1$, then one's confidence at $t i$ that one feels cold is not reliably based' (Williamson, 2000, p. 97).

iii. But I believe that I feel cold at $t i$.

Steps (i) to (iii) render the logical conclusion that if I know at $t i$ that I feel cold, then I shall feel cold at $t i+1$. Let us call this conclusion the margin-for-error principle $(\mathrm{R})$ (Williamson, 2000, p. 114; Berker, 2008, p. 4; Brueckner \& Fiocco, 2002).

With this principle at hand, Williamson can very easily derive the anti-luminosity thesis.

i. Let us suppose that feeling cold is a luminous condition.

ii. I feel cold at dawn at $t 0$.

iii. If I feel cold at dawn, then I know that I feel cold at dawn, since feeling cold is a luminous state at $t 0$.

iv. Hence, I know that I feel cold at dawn (MP, 2-3).

v. If I know it, then I shall feel cold at $t i$ one millisecond later, given (R).

vi. Hence, I feel cold at $t i$.

vii. But if I feel cold at $t i$, then I know that I feel cold at $t i$, if the condition feeling cold is luminous.

viii. Then, I know that I feel cold at $t i$ (MP 6-7).

ix. If I know that I feel cold at $t i$, then I shall feel cold at $t i+1$, given (R), and so forth.

$\mathrm{x}$. This progression yields to the conclusion that I shall feel cold at noon.

xi. But I do not feel cold at noon, by construction of the example.

xii. Hence a contradiction follows because I do not feel cold at noon.

Given this contradiction, something has gone wrong in the meantime. Williamson immediately identifies the culprit. It is not true that the condition of feeling cold is always luminous. Given our discriminatory capacities, there are limits to our knowledge of this condition at certain periods of time between dawn and noon.

Most of the pressure against Williamson's anti-luminosity argument has focused on his acceptance of principle (R). This principle summarizes the idea that knowledge 
requires reliability if this knowledge should be safe enough. I shall remember a much quoted passage of Williamson's book to keep in view this idea in its more refined version.

Consider a time $t i$ between $t 0$ and $t n$ and suppose that at $t i$ one knows that one feels cold. Thus one is at least reasonably confident that one feels cold, for otherwise one would not know. Moreover, this confidence must be reliably based, for otherwise one would still not know that one feels cold. Now at $t i+1$ one is almost equally confident that one feels cold, by the description of the case. So if one does not feel cold at $t i+1$ then one's confidence at $t i$ that one feels cold is not reliably based, for one's almost equal confidence on a similar basis a millisecond earlier that one felt cold is mistaken. In picturesque terms, that large portion of one's confidence at $t i$ that one still has at $t i+1$ is misplaced. Even if one's confidence at $t i$ was just enough to count as belief, while one's confidence at $t i+1$ falls just short of belief, what constituted that belief at $t i$ was largely misplaced confidence; the belief fell short of knowledge. One's confidence at $t i$ was reliably based in the way required for knowledge only if one feels cold at $t i+1$. (Williamson, 2000, p. 97)

So the basic train of thought is this. I have almost the same confidence that I feel cold at one millisecond intervals $t i, t i+1, t i+2$, etc. If I had not felt cold at, let's say, $t i+1$, then my confidence that I felt cold at $t i$ would have not been reliably based. But given that my confidence at $t i$ was reliably based, by construction of the case, then I shall feel cold at $t i+1$.

The margin-for-error principle $(\mathrm{R})$ together with the reliability condition squeezes our argumentative capacities between two strong but opposite forces. The first principle makes us to accept that if I know at $t i$ that I feel cold, I will feel cold at $t i+1$. The reliability condition makes us assume that I shall feel cold at $t i+$ 1 if I reliably knew that I felt cold at $t i$. Since I know at $t i$ that I feel cold and I know it reliably, then I shall feel cold at $t i+1$. Williamson thinks that this straitjacket is unavoidable. So he decides to abandon the luminosity condition to avoid the contradiction that has been generated as a consequence of accepting this condition.

Despite its apparent overwhelming simplicity, the anti-luminosity argument is very complex and implies premises and conclusions that are problematic on many sides. My strategy will be threefold. First of all, I shall argue that since it is possible to generate a logical contradiction from the common sense example together with the presuppositions that Williamson endorses, it is not clear at all that we should abandon the luminosity principle instead of principle (R). If we keep both principles, a logical contradiction follows, but the logical structure of the argument does not allow us to decide which one we should eliminate to avoid the contradiction. This is a sceptical conclusion in the classical sense because we can generate two logical arguments that render two contradictory conclusions which, nevertheless, have the same persuasive force from a rational point of view. 
Second, Williamson should table reasons other than logical ones to prefer principle (R) rather than the principle of luminosity to avoid a sceptical scenario. In Williamson's case, these other reasons are psychological. However, I shall argue that the kind of picture that Williamson provides of our psychological life is not plausible. Williamson has a very problematic idea of our mental life in that he implicitly assumes that some well-known psychophysical correlations are also valid for the 'inner' scenario of the mind. But this is not the case.

Third, I shall dwell on Williamson's idea that feeling cold or feeling less cold is an instance of knowing p. Prima facie feeling less cold is a case where one knows something. When we feel less cold, we somehow know that we are less cold. However, the anti-luminosity argument implies that we might not be in the position to know that we know it. In this third part of my argument, I shall critically dwell on Williamson's proposal that there has to be a blackout agent that blocks our cognitive access to mental states that we nevertheless experience and are open-to-view (Williamson, 2000, p. 94).

\section{An Impossible Decision to Be Made on Logical Considerations}

The first part of my argument is that eliminating the principle of luminosity does not have more logical force than eliminating principle $(R)$ as the right strategy to avoid the contradiction that has been drawn. Both movements are equally convincing from a logical point of view. This means that there is nothing logically wrong with Williamson's argument. However, there is nothing logically wrong with the opposite argument either. In the first deduction, the principle of luminosity is introduced as a hypothesis and principle $(\mathrm{R})$ as a valid axiom. Since a contradiction follows from the introduction of the hypothesis, we must reject the principle of luminosity. This is the path that Williamson follows. In the second deduction, I proceed the other way around. I introduce principle (R) as a hypothesis and the principle of luminosity as a correct axiom. Since a contradiction also follows, we should abandon principle (R). From a logical point of view, both deductions are equally valid, and we cannot discard the conclusion that follows from one of them based on the conclusion that follows from the other one. Stalemate!

\subsection{Logical Formalization of Williamson's Argument Against the Luminosity of All Our Mental states}

\subsubsection{The Language}

There are two predicates:

$F i=$ Feeling cold at a given moment in time $i$.

$K j=$ Knowing at time $j$ that one feels cold at $i$.

It might well be the case that $j$ and $i$ are identical. This is what happens when knowledge or cognition is the same as being aware or conscious of what one feels. 
But it is also possible that our knowledge might be the consequence of remembering that we have felt cold. In this case $j$ and $i$ are not identical.

Both predicates, $F i$ and $K j$ are attributed to actual mental states. I shall use lower case Greek letters to represent them. Thus $\alpha$ is the name of an individual or mental state. And $F i(\alpha)$ expresses that there is a mental state that consists of feeling cold at $t i$.

I express Williamson's idea that at $t i$ one knows that one feels cold thus:

1. $F i(\alpha)$ says that the mental state I feel cold takes place at $t i$.

2. $K j(\beta)$ says that, simultaneously, the mental state - a different mental state to the previous one $\mathrm{Fi}$ - of knowing that the mental state $F i(\alpha)$ takes place. Notice that $\beta$ and $\alpha$ express different facts. An equivalent expression to $K j(\beta)$ would be $K j$ (“Fi( $\alpha)$ ").

\subsubsection{The Principles}

Principle of luminosity: $\forall x[F i(x) \rightarrow \operatorname{Si}(“ F i(x)$ ") $)]$

Margin-for-error, Principle (R): $\forall x[(\operatorname{Si}(“ F i(x) ")) \rightarrow \exists y(F i+1(y))]$

\subsubsection{First Deduction-Axiom: Principle R}

Keys:

$\mathrm{A}=\mathrm{It}$ 's not cold at noon

$\mathrm{B}=\mathrm{It}$ 's cold a little before noon

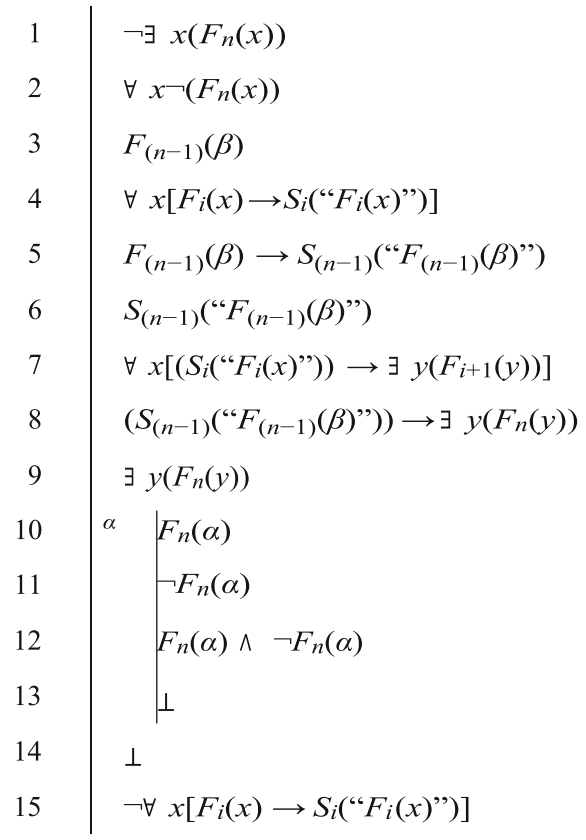

Datum 1: A. Temporary subscript: $n$

$\exists$ negation: 1

Datum 2: B. Temporary subscript: $n-1$

Hypothesis: Principle of luminosity

$\forall$ elim: $4, \mathrm{i} /(\mathrm{n}-1), \mathrm{x} / \beta$

MP: 5, 3

Principle (R) (axiom)

$\forall$ elim: $7, \mathrm{i} /(\mathrm{n}-1), \mathrm{x} / \beta$

MP: 8,6

Hypothesis: $\exists$ elim: 9

$\forall$ elim: $2, \mathrm{x} / \alpha$

$\wedge$ intro: 10,11

ECQ: 12

$\exists$ elim: $10-13$

Red. Abs. 4-14 


\subsubsection{Second Deduction-Axiom: Principle of Luminosity}

The language and the principles are the same as in 3.1.1 and 3.1.2. Keys:

$\mathrm{A}=\mathrm{It}$ 's not cold at noon

$\mathrm{B}=$ It's cold a little before noon

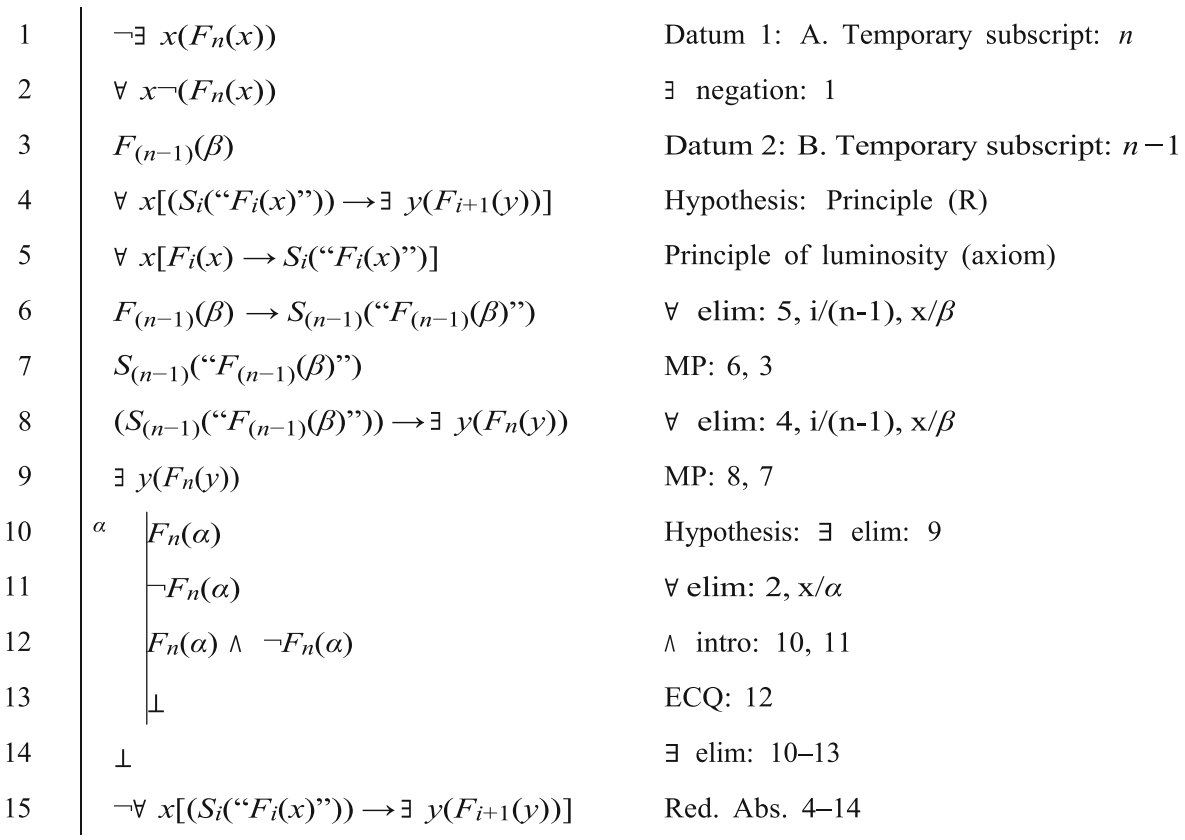

These two deductions are logically valid and generate a sceptical antinomy. From a logical point of view, it is not more reasonable to eliminate the principle of luminosity than to eliminate principle (R). In this sceptical scenario, if Williamson wants to convince us that we should still get rid of the principle of luminosity, he should provide us with new reasons to do so. These other reasons are psychological and epistemological in nature. However, I shall argue that the psychological reasons presuppose an untenable picture about our mental life. And his epistemological considerations imply some ideas about the causes of the limits of our reflective knowledge of mental states that make these limits difficult to understand.

\section{Psychological Problems}

Williamson introduces a very problematic presupposition that determines his whole argument. Steup calls it the Non-Awareness Change Principle (NAC) (Steup, 2009, p. 218).

Suppose that one's feelings of heat and cold change so slowly during this process that one is not aware of any change in them over one millisecond. (Williamson, 2000, p. 97) 
I agree with Steup that this thesis is pivotal in Williamson's argument and I shall also concentrate on it. It implies that we should accept that the qualitative contents of the subject's feelings might actually change in a very subtle way, but they do it so delicately and progressively that 'one is not aware of any change' from one millisecond to the next, although such tiny changes have actually taken place while the subject is experiencing these feelings and changes. This supposition leads us to the problematic acceptance that there is a clear gap between changes in the intentional content of the feelings that we are experiencing and our awareness, hence the knowledge, of these changes. According to traditional analysis of mental states, having knowledge of our feelings and of their qualitative content derives from our awareness of them. But Williamson thinks that we can have these feelings, i.e. we can experience them and, hence, experience their qualitative content, without being aware of any changes in these qualitative contents.

The notion of experience that Williamson is using here is problematic because it is based on an untenable conception of our psychology. The intentional content of one's subjective feelings might qualitatively change every millisecond. As a consequence, we will have or experience feelings of the same kind - feelings of temperature, as it werebut with different subjective quality - more or less cold. Changes in feelings come from changes in their intentional, qualitative content. Nevertheless, one might not be aware of these small changes, even though we experience feelings with these changing qualitative contents and, according to Williamson's externalism, we know about them. One might actually consider with undivided and full attention whether one feels less cold at each moment during the process. Williamson claims that the acute and exhaustive attention to the qualitative content of one's feelings will progressively weaken one's confidence that one feels cold (Williamson, 2000, p. 97). I agree with him. But Williamson's presupposition also implies that our careful and sincere attention to our feelings during each millisecond is unable to disclose that they have actually changed given that the content of these feelings has also changed. Subjective cognitive access to changes in the content of many mental states through our experience of the feelings that we are having and their content is blocked for some reason. This is why we are not in a position to know that we are less and less cold during the many tiny milliseconds existing between dawn and noon, even though we experience changes in feelings because we experience changes in their qualitative content and we know about these contents. Nevertheless, they are non-luminous at many times.

One psychological problem with non-luminous mental states is that they force us to ask about the relationship between experiencing, knowing and consciousness. On the one hand, experiencing non-luminous mental states should be compatible with knowing about them - experiencing is a kind of knowing - but also with the possibility of not being aware of changes in the qualitative content of the mental states that we are experiencing. In this case, experiencing and knowing are not directly related to consciousness. On the other hand, there are luminous states in which experiencing and knowing are internally related to consciousness. We know about the mental states that we are experiencing and about their contents because we are aware of them. In this other case, experiencing, knowing and consciousness are constitutively or internally related. Thus, Williamson owes us an explanation about why experience and knowledge can be detached from consciousness in the case of non-luminous mental states 
despite the fact that these states are not unconscious in any of the main uses of this notion. Williamson has never talked about them being unconscious but as being nonluminous, which seems to be quite a different category.

It seems to me that Williamson is proposing a new and extraordinary kid on the block that, nevertheless, profusely populates our ordinary mental experience at almost every millisecond of our conscious life. There are mental states that we are experiencing but whose contents are completely inaccessible to us. The fact that we are experiencing these states does not accompany our awareness of their contents and changes. These states are out of reach of phenomenological investigation and have been systematically ignored by contemporary philosophers of mind. This is the reason why a logic-based argument is needed to find out more about their existence.

I have argued that the problem is not with the logical argument. Williamson is right both in his deduction and his conclusion. However, his logical argument is not decisive since the opposite conclusion can also be drawn from an equally valid deduction. The problem lies with the most general psychological presupposition on which his argument is based and from which his logical machinery starts working. My point is that Williamson has implicitly and wrongly transposed what is common knowledge about some well-known psychophysical correlations to the 'inner' mental scenario. This transposition has permeated Williamson's presupposition and makes it quite problematic.

To argue this point, I shall use the concept of cognitive sensitivity. Williamson has put forward the notion of sensitivity and has related this concept to a family of other modal notions such as safety, stability and robustness that refer to modal states (Williamson, 2000, p. 123). For him, these concepts 'concern what could easily have happened [. . . ] under small variations in the initial conditions' (Williamson, 2000, p. 123). I like the concept of sensitivity, but I shall completely change its focus so that it matches certain theoretical needs that have appeared in the previous discussion. This reworking of the concept is useful to analyse why Williamson thinks that many mental states are non-luminous.

I shall start distinguishing between full sensitivity and partial sensitivity. A condition or state is fully sensitive to another condition or state if and only if variations, even very small ones, in the latter condition or state covary in an exact way and in the same degree with variations in the former condition or state. A condition or state is partially sensitive to another condition or state if there is a covariation between the two of them but there is not a direct one to one correspondence. Each small variation in the latter is not reflected by a small variation in the former.

I shall give an example of what I mean by partial sensitivity which can also be used to understand the notion of full sensitivity. The example has to do with cases of psychophysical sensitivity. The Fechner-Weber psychophysical law is based on the fact that not every single but measurable variation, from a third-person's point of view, in the external stimulus (increases of one milligram each millisecond, for example) is accompanied by corresponding variations in subjective feelings, although a logarithmic mathematical relation can be established between the objective increase in the stimulus and the subjective feelings. Unnoticed to the subject, there might have been an objective and measurable change in the intensity of the stimulus. The Fechner-Weber psychophysical law establishes that the subjective sensation is proportional to the natural logarithm of stimulus intensity (Fechner \& Gustav, 1860 II, 13; Kandel et al., 
2012, 451; Rand, 1912, 569). ${ }^{1}$ Each variation of one milligram each millisecond is not accompanied by changes in the subject's feelings of weight. Given that the subjective feelings do not covary in the same degree with variations in the objective and measurable intensity of the stimulus, we can conclude that the former condition is not fully sensitive to the latter.

However, subjective feelings are partially sensitive to the stimulus. After several tiny increases in the stimulus, the subject might experience a conscious and noticeable change in how he feels the weight of the object that is placed on his hand. Borrowing some useful terminology from Steup, we can say there are some 'discernible changes' from a third-person point of view in the weight of the object that the subject can also discern, although the subject cannot discern all the tiny and objective changes in the weight of the object that have occurred between two episodes of discernible changes (Steup, 2009, p. 221). I shall coin the expression 'cognitive hole' to refer to cases where the subject gains access to discernible changes in the objective stimulus. However, in between two episodes in the awareness of changes in the weight of the object, i.e. between two cognitive holes, there are many changes in the objective weight of the object that the subject is completely unaware of. These changes remain indiscernible to him. There are limits to the discernment capacity of our senses (Williamson, 2000, pp. 103-104). The natural causes of why this is so are of no concern at this point. Nevertheless, this is a case of partial sensitivity that we can now describe as the intermittent appearance and disappearance of cognitive holes.

Once we have the distinction between partial and full sensitivity, it is my contention that this widely accepted knowledge about the relationship between objective stimulus and subjective feelings, as expressed by the Fechner-Weber psychophysical law, can help us understand Williamson's presuppositions in his arguments for the non- luminosity of many mental states. However, in Williamson's new scenario, all characters that are going to play an important role belong to the realm of mental subjectivity. Thus, feeling progressively less and less cold plays the role of the objective stimulus in the previous example, i.e. of the object having increasingly more and more weight. Hence, awareness of feeling less and less cold plays the role of awareness of feeling more and more weight. Now it is time to establish the parallelisms to show that there has been a mistaken transposition of psychophysical correlations to 'psycho-psycho' correlations within the mind, and this has some important consequences.

To start with, we should assume that in Williamson's scenario there are some discernible subjective feelings because the subject is aware of the content of these feelings. For example, the subject feels cold at dawn and luminously knows it but does not feel cold at noon and also knows it. In this case, feeling such and such is the same thing as being aware of it and, hence, knowing it. It is also clear that the subject has cognitive holes that allow him to have cognitive access to his feelings and to their qualitative content at certain periods of time. Very probably, there are various cognitive holes between dawn and noon since common knowledge and practice tells us that the subject consciously feels less cold between dawn and noon and acts accordingly. This

\footnotetext{
${ }^{1}$ It is a well-known fact that some adjustments should be made for different modalities of sensory experience. For some of them, 'the relationship between the stimulus magnitude and the perceived intensity is linear, that is, a power function [not a logarithmic relationship] with a unity exponent $(n=1)[I=K(S-S 0)]^{\prime}$ (Kandel et al., 2012, 451).
} 
is why he takes off his coat first and his jumper later on. However, the subject cannot discern all the tiny changes in his feeling less cold that occur at one-millisecond intervals between dawn and noon or between any other two cognitive holes. He has no cognitive access to these changes because, so to speak, the entrance to the cognitive hole is now closed. According to Williamson, in between two episodes of the awareness of gradually feeling less cold, there have been many changes in the feelings that the subject is experiencing. Nevertheless, he is not in a position to know the many changes that have occurred in the qualitative content of these feelings because he has no access to them, although such changes have actually taken place while he was experiencing the feelings. He experiences them, but they are not luminous to him. There is no constitutive relation between experiencing and knowing in the sense of knowing what we know when we are experiencing the feeling of cold or of being less cold. In Barker's terms:

If Williamson's anti-luminosity argument succeeds, then it is possible for us to be epistemologically disengaged (that is, disengaged at the level of knowledge [of knowing what we know because we are experiencing it]) from our mental states [. .. ]; but he can only establish that conclusion assuming that, even after ideal reflection, we can be doxastically disengaged (that is, disengaged at the level of belief) from a given mental state. (Berker, 2008, p. 19)

Williamson construes his case for anti-luminosity as one in which there is only partial sensitivity between the subject's awareness of feeling less cold and actually feeling less cold. There is an on-and-off sequence of possible states in the cognitive holes along the process. However, unlike the case of psychophysical correlations, we do not know of any mathematical relationship between the awareness of the feeling and the feeling itself in this inner scenario of the mind. We do not even know how we could start providing such a mathematical correlation.

Steup summarises Williamson's position correctly:

So in between each minimally discernible change of feeling less $\varphi$ [less cold], one undergoes a multitude of indiscernible changes of feeling $\varphi$. That is how we must understand Williamson's key assumption about case $\alpha$. In case $\alpha$, we have many intervals of the following kind: in $\alpha i+1$ one feels less cold than one did in $\alpha i$, but this change is indiscernible. Therefore, one remains unaware of it. If we assume that a minimally discernible change takes at least one second, then we have within that second many indiscernible occurrences of feeling less cold than before. (Steup, 2009, p. 221. Cf. (Williamson, 2009))

The fact that the subject is not aware of changes in his feeling less cold does not mean that there have not been changes in this state. He is experiencing many feelings of this kind, but he is not aware of changes in their intentional content (De Florio \& Fano, $2020,5)$. At the time, he is not in a position to know that these changes have occurred in between episodes of awareness of feeling less cold even though he experiences them. The content of these feelings is not luminous.

I think that the existence of a strong but faulty correlation between the psychophysical example and the 'psycho-psychological' example poses some important 
philosophical difficulties. This lack of correlation has been also pointed out by Berker but in a different way (Berker, 2008, p. 19). First of all, it implies an extreme and unnecessary reification of the mind because it leads us to think that something similar to psychophysical objective correlations also occurs in the mind between gradual changes in the qualitative content of our feelings and our awareness and knowledge of these changes. Second, it is also a case where we lack one main feature of the psychophysical correlation, namely, an objective measure from a third-person's pointof-view of the decrease in feeling less cold. There is no such thing in the mental scenario case because, if there were such an objective measure, then the indiscernible changes in the contents of our mental states obtained in between discernible changes of feeling less cold would no longer be indiscernible. This is actually the main difference with the psychophysical example. It is also the reason why Williamson arrives at the conclusion that there are indiscernible, non-luminous mental states through logical reasoning and not through phenomenological methods of analysis or through the usual tools that are employed in the philosophy of mind. It is impossible to have knowledge of their existence by these means precisely because they are phenomenologically nonluminous, although we experience them.

Nevertheless, the most difficult problem that Williamson would have to face is to provide a theory of consciousness in which we can completely detach experiencing feelings and their qualitative content from our awareness of their intentional contents even though we know about them. This seems to be a difficult task as I have already argued. Notice, however, that I do not need to enter into the discussion about whether or not the impossibility of this detachment is a question of conceptual or metaphysical necessities, as Steup suggests (2007, p. 225). On the contrary, it looks more like a contingent fact about human beings. However, for my general argument, nothing depends on the possible distinction between metaphysical necessities and contingent facts.

\section{Reflective Meta-knowledge and Its Limits}

Although Williamson has tried to argue that many mental states, probably millions, are non-luminous, he has not tackled in detail two questions that might spontaneously be asked about his position. First, what is the agent or factor that causes the condition of feeling less cold to often be non-luminous when it is the case that we have luminously known that we felt cold at a given time? What, then, causes some cognitive holes to intermittently open and close? Second, why is it that this agent or factor starts operating? Why is the agent not working at certain moments but at many other times switches on? Is there a mechanism or a reason for that? However, these two questions are dependent on a previous one. Why should we pose the problem in terms of a blocking agent that switches on and off? Williamson does not have an answer to this question, although the consequences of this lack are very problematic. To deal with this problem in more detail, it is necessary to go back to the analysis of the most basic concepts that have led him to the anti-luminosity thesis.

Williamson explains the concepts of luminosity and anti-luminosity in terms of the complex notion of 'being in a position to know', which he regards as 'somewhat vague and context-dependent' but sufficient for his purposes, this vagueness notwithstanding 
(Williamson, 2000, p. 95). He indirectly characterizes this notion in terms of what is not necessary and is not sufficient to be in a position to know $p$. 'To be in a position to know $p$, it is neither necessary to know $p$ nor sufficient to be physically and psychologically capable of knowing $p^{\prime}$ (Williamson, 2000, p. 95). It is clear that something can be 'open to one's view, unhidden, even if one does not yet see it' (Williamson, 2000 , p. 95). For the sake of clarity, I shall use capital letters to refer to the condition about which Williamson asks whether it is luminous or anti-luminous depending on whether or not we are in the position to know that the condition, say $P$, is given.

It is easy to find everyday examples where we do not know $P$ but we are in a position to know $P$ because we are physically and psychologically capable of knowing $P$. This is specially the case when we think about objects or situations or states of affairs in a wide sense. Suppose $P$ is a landscape or a mathematical theorem. A landscape or a mathematical theorem can be respectively seen or understood and thus known by many people. However, this does not necessarily mean that any of us actually sees the landscape or understands the mathematical theorem. Even though we might be in a position to know $P$, we do not necessarily know $P$. I might not see the landscape because I am not in the right place to do so and thus know the landscape. However, I might be in a position to see it in the sense of being able to, if I were rightly placed. I might have not understood a mathematical theorem when it was first presented to me in class because I had not studied geometry. However, I am in a position to understand it and thus know the theorem, if I study it. I have the cognitive and physical capacities, among others, to reach an understanding of it. In both cases 'being in a position to know $P$ ' means that nothing substantially insurmountable or a priori will block the path of our accessibility to know $P$.

Steup was wrong in uncritically assuming that "non-mental conditions are nonluminous' on the basis that I do not always know if, for example, there is milk in the refrigerator (2009, p. 217). According to Williamson, and also to common sense, I am in the position to know that there is milk in the refrigerator. This is a non-mental condition and yet a luminous one. Therefore, the basic idea is that if a luminous condition obtains in a given case, then if one does not already know that the condition obtains, one could come to know that it does merely by taking the time to carefully reflect on the matter' (Berker, 2008, p. 2).

Williamson characterises anti-luminosity based on, and in sharp contrast to the vague notion of luminosity. And he considers that the condition $P$ about which he asks whether it is luminous or anti-luminous might be a complex one like $S$ know $p$ or $S$ feels less cold. The condition $S$ knows $p$ is luminous when $S$ is in the position to know that $S$ knows $p$. The condition $S$ knows $p$ will be anti-luminous when $S$ is not in the position to know that $S$ knows $p$ even though the condition $S$ knows $p$ obtains. Reflective meta-knowledge has its limits for some reason yet to be identified. The same limitation happens with condition $P$, when $P$ is the complex condition $S$ feels less cold. The condition $S$ feels less cold is luminous if the subject is in the position to know that the condition obtains in each particular case. The condition is not luminous when $S$ is not in the position to know that $S$ feels less cold even though the condition $S$ feels less cold actually obtains.

What needs to be explored now is how we should define the negative notion of 'not being in a position to know $P$ ' and how we do this in relation to the unnecessary and insufficient conditions that had characterized the positive notion of 'being in a position 
to know $P^{\prime}$. I have remarked that when $P$ is a complex condition such as $S$ knows $p$ or $S$ feels less cold it is not necessary to know $P$ for $P$ to be a luminous condition. And it is not sufficient to be physically and psychological capable of knowing $P$. Now one thing seems to be clear enough in the case of anti-luminosity. It is necessary that $S$ knows $p$ if $S$ is not going to be in the position to know that he knows $p$. This is a way of phrasing Williamson's externalist position. $S$ might know $P$ although he is not in the position to know that he knows it. In the same way, it is necessary to feel less cold, if, according to the anti-luminosity thesis, we are not going to be in the position to know that we feel less cold.

This might sound very strange but in fact it is an analytic proposition. The fact that we are not in the position to know that we know $p$ does not affect the fact that we know $p$, at least from Williamson's externalist epistemological perspective. The former is a meta-state in relation to the latter. The anti-luminosity thesis says that there are many instances of feeling less cold or of knowing $p$ that we do not know even though we feel actually less cold or we know $p$.

It is more difficult to make clear the relationship between our physical and psychological capabilities to know a certain condition and the non-luminosity of such a condition (feeling cold or pain, knowing $p$, etc.). Williamson makes the following remark to highlight this relationship:

Thus, it does not follow from the non-luminosity of a condition that there are cases in which, although it obtains, one is not physically and psychologically capable of knowing that it obtains. (Williamson, 2000, p. 109)

Hence, a condition might be non-luminous even though we are physically and psychological capable to knowing it. This thesis looks also very strange at first sight. A possible interpretation is that one can be physically and psychologically capable of knowing $P$ - knowing that one feels cold or, more generally, knowing that one knows $p$ - even though one cannot know $P$ no matter whether one is in the right place to know $P$ or has gone through the right learning process to know $P$. However, this interpretation leaves us in a state of total confusion. If we are physically and psychologically capable of knowing $P$, why is it that we cannot know $P$ ? When $P$ is the condition of knowing $p$, then we can be physically and psychologically capable of knowing $p$ and yet not be in the position to know that we know $p$. When $P$ is the condition of feeling less cold, then one can be physically and psychological capable of knowing that he feels less cold and yet not being in the position to know that he feels less cold. And here 'cannot' should be taken in the strong sense of the word. We cannot know $P$ because there is no place or learning process that will bring us closer to knowing $P$. We cannot know that we know p for the same kind of reasons. But if we cannot know that we know $P$, in what sense, then, can we say that we are physically and psychologically capable of knowing $P$ although we are not in the position to know $P$ ? How do you know that you know $P$ in the first place?

There is, however, a more positive interpretation that could avoid this puzzling situation. Williamson would be warning us against the idea that if a condition is nonluminous, it is always due to the fact that we are in a wrong or unfavourable physical or psychological situation in relation to it. This implies that no empirical improvement of our psychophysical situation will turn the anti-luminous condition into a luminous one. 
Or rather, the non-luminosity of a given condition does not always have as its cause or grounds some subjectively inappropriate empirical circumstances (illness, being handicapped, limited memory, limited instruments, limited logical resources, etc.) that might be improved to overcome the non-luminosity of the condition. But if this is so, what is then the source or origin of the non-luminosity of the condition? If it is not the psychophysical subject, there seem to be only two other alternatives. It is either the objective properties of the condition that make it non-luminous for the subject or something that stands between the condition and the subject and blocks our cognitive access to the condition.

If the non-luminosity of a condition were an objective property of such a condition, it would make no sense to say that we could be physically and psychologically capable of knowing it, as Williamson has claimed, since we would not be able to know it given its ontological structure. The objective properties of the situation that make it nonluminous would prevail over the psychophysical capabilities of the subject of being in a position to know it. If the condition would be this sort of indestructible and unreachable ontological bunker, Williamson could not say that we are physically and psychologically capable of knowing the condition although we are not in the position to know it. This would never be the case if the non-luminosity of the condition belonged to the condition itself.

The non-luminosity of a condition $P$ - knowing $p$, feeling less cold, etc.- has therefore to do with the kind of relationship that exists between an individual who might have the appropriate circumstances to know $P$ and the condition that he tries to know but is not in the position to know. The non-luminosity of a condition is related to our access to it that goes beyond the appropriate physical and psychological circumstances of the individual. These personal circumstances might be the right ones and yet the condition might be non-luminous. I would only add that what blocks our access to the condition we want to know and makes it non-luminous should not be removable for vulnerable beings like us, given our present constitution. If the blocking agent were removable by some kind of improvements, then there would be a right place or a learning process that might put us in the position to know $P$ (knowing that we feel cold, knowing that we know $p$ ). This is what characterizes unconscious mental states, according to Freud. The blocking, repressing agent can be overcome or at least partially avoided through the right psychoanalytical therapy, and so the unconscious mental state can become conscious. Wo Es war soll Ich werden. But an anti-luminous condition is defined by the fact that we are not in the position to know such a condition in absolute terms. So, only the hypothesis of the existence of an insurmountable blocking agent would make sense of the fact that we might have the right psychophysical circumstances to know $P$ and, nevertheless, not be in a position to know $P$ that is not merely accidental and surmountable through spatiotemporal displacements, learning processes or any other kind of improvements (memory, attention, instruments, therapy, etc.). And other question would be whether it is pragmatically relevant to make all these distinctions since, if we take a look at their consequences, it is indifferent to say that a condition is non-luminous because we do not have the right psychophysical circumstances to gain access to it, because the condition itself is non-luminous - it is a kind of ontological black hole — or because there is an insurmountable blocking agent between us and the condition. 
In fact, this latter seems to be Williamson's option. To make this point clear, we need to take a look at how he characterizes a luminous condition. For a condition to be luminous, it is required that 'no obstacle must block one's path' to knowing $P$ (Williamson, 2000, p. 95). Luminosity obtains because there is nothing that hinders $a$ priori or substantially our knowing condition $P$. Correspondingly, if there are nonluminous conditions, it is because there is such a blocking agent. However, saying this is not enough to identify this blackout agent and thus answer the 'What' question: what blocks our capacity to know $P$ ? Williamson does not answer what has interfered between the agent and the condition $S$ feels less cold so that $S$ is not in the position to know that he feels very gradually less cold. The subject luminously knows that he felt cold at dawn, but he is no longer in the position to know that he feels less and less cold during many milliseconds afterwards between dawn and the afternoon. And indirectly saying that something must block one's path to know $P$ is not sufficient to explain why this blocking agent switches on and off, as it seems to be the case according to the argument I have developed in the previous section.

Then, it is not clear what this blocking agent might be in the case of the nonluminous condition $S$ feels less cold. There is always some impossibility of acquiring reflexive meta-knowledge about something that we already know because, for example, we feel it. I have explored in this section the kind of problems that Williamson might need to face to defend this epistemological thesis in the case of mental states.

\section{Conclusion}

Williamson has put forward a logical argument to defend that many mental states are non-luminous. I have argued that his logical argument is correct but not conclusive to establish the anti-luminosity thesis because there is an equally valid logical argument from which his conclusion does not follow. This other argument challenges one of the main presuppositions on which Williamson's case rests, namely, the validity of principle $(\mathrm{R})$. This opens a sceptical scenario. Hence, if he still wants to convince us that the anti-luminosity thesis is philosophically robust he needs to provide other kind of arguments.

Anti-luminosity implies some views about human psychology, and I have analysed whether these views can be used to choose one horn of the sceptical dilemma rather than the other. However, I have argued that they cannot make this service because they cast an unrealistic shadow on our mental life. Particularly they require that some well- known psychophysical correlations are also valid for the inner scenario of the mind. But this is not the case. Finally, I have explored in the last section the kind of problems that Williamson might need to face to make sense of the idea of "not being in the position to know condition $P$ ' that he uses to characterize the anti-luminosity of some conditions such as $S$ feels very gradually less cold. The conclusion of this last analysis is still fresh in the mind of the reader. It is not clear what blocks our access to condition $P$ or why we should pose the problem in these terms. Hence, Williamson's argument in favour of the anti-luminosity of many mental states is not conclusive. 
Acknowledgements This paper has been written within the Research Project: "Cognitive Vulnerability, Verisimilitude and Truth" (FFI2017-84826-P) of the National Program for Research, Development and Innovation of the Spanish Ministry of Science and Research.

Funding Open Access funding provided thanks to the CRUE-CSIC agreement with Springer Nature.

\section{Declarations}

Conflict of interest statement On behalf of all authors, the corresponding author states that there is no conflict of interest.

Open Access This article is licensed under a Creative Commons Attribution 4.0 International License, which permits use, sharing, adaptation, distribution and reproduction in any medium or format, as long as you give appropriate credit to the original author(s) and the source, provide a link to the Creative Commons licence, and indicate if changes were made. The images or other third party material in this article are included in the article's Creative Commons licence, unless indicated otherwise in a credit line to the material. If material is not included in the article's Creative Commons licence and your intended use is not permitted by statutory regulation or exceeds the permitted use, you will need to obtain permission directly from the copyright holder. To view a copy of this licence, visit http://creativecommons.org/licenses/by/4.0/.

\section{References}

Berker, S. (2008). Luminosity Regained. Philosophers's Imprint, 8-2, 1-22.

Brueckner, A., \& Fiocco, O. (2002). Williamson's Anti- luminosity Argument. Philosophical Studies, 110, 285-293.

De Florio, C., \& Fano, V. (2020). Williamson On the Margins of Knowledge: A Criticism. Foundations of Science. https://doi.org/10.1007/s10699-020-09715-8 1-13.

Fechner, \& Gustav, T. (1860). Elemente der Psychophysik. Leipzig: Breitkopf und Härtel.

Kandel, E. R., Jessel, Th. M., Schwartz, J. H., Siegelbaum, Steven A., Huspeth, A.J. (2012). Principles of neural science (5th ed.). MacGraw-Hill.

Kriegel, U. (2009). Subjective consciousness: A self-representational theory. Oxford University Press.

Kriegel, U., \& Williford, K. (2006). Self-representational approaches to consciousness. The MIT Press.

Neta, R., \& Rohrbaugh, G. (2004). Luminosity and the Safety of Knowledge. Pacific Philosophical Quarterly, $85,396-406$.

Rand, B. (Ed.) (1912). The Classical Psychologists. Translation by Herbert Sidney Langfeld of sections VII and XVI of Gustav Theodor Fechner's Elemente der Psychophysik (1860) [Elements of psychophysics] (562-572). Boston: Houghton Miffl Reprinted in Herrnstein, R. J. and Boring, E. G. (Eds.)(1965). A Source Book in the History of Psychology (66-75). Cambridge, Mass.: Harvard University Press.

Steup, M. (2009). Are mental states luminous? In: P. Greennough \& D. Pritchard (Eds.), Williamson on knowledge (pp. 217-236). Oxford University Press.

Tennant, N. (2009). Cognitive phenomenology, semantic qualia, and luminous knowledge. In: P. Greennough \& D. Pritchard (Eds.), Williamson on knowledge (pp. 237-256). Oxford University Press.

Williamson, T. (2000). Knowledge and its limits. Oxford University Press.

Williamson, T. (2009). Reply to Matthias steup. In: P. Greennough \& D. Pritchard (Eds.), Williamson on knowledge (pp. 370-374). Oxford University Press.

Publisher's Note Springer Nature remains neutral with regard to jurisdictional claims in published maps and institutional affiliations. 